Global COE Hi-Stat Discussion Paper Series 148

$$
\begin{aligned}
& \text { Research Unit for Statistical } \\
& \text { and Empirical Analysis in Social Sciences (Hi-Stat) }
\end{aligned}
$$

\title{
Endogenous Ranking and Equilibrium Lorenz Curve Across (ex-ante) Identical Countries
}

Kiminori Matsuyama

August 2010

Hi-Stat 


\title{
Endogenous Ranking and Equilibrium Lorenz Curve Across (ex-ante) Identical Countries ${ }^{1}$
}

\section{By Kiminori Matsuyama}

\section{Last revised: 7/9/2010 4:10 PM}

\begin{abstract}
This paper considers a model of the world economy with a finite number of ex-ante identical countries and a continuum of tradeable goods. Productivity differences across countries arise endogenously through free entry to the local differentiated producer service sector in each country. It is shown that, in any stable equilibrium, the countries sort themselves into specializing in different sets of tradeable goods and that a strict ranking of countries in income, TFP, and the capital-labor ratio emerge endogenously. The equilibrium Lorenz curve is characterized by a second-order nonlinear difference equation with the two terminal conditions. As the number of countries increases, this equation converges to a differential equation whose unique solution can be solved analytically and depends on a few parameters in a tractable manner. This enables us to show when the equilibrium distribution obeys a power-law and how various forms of globalization affect inequality among countries and to study the welfare effects of trade.
\end{abstract}

Keywords: Endogenous Comparative Advantage, Endogenous Inequality, Globalization and Inequality; Dornbusch-Fischer-Samuelson model; Dixit-Stiglitz model of monopolistic competition, Symmetry-Breaking, Lorenz-dominant shifts, Log-submodularity; Power-law distributions

\footnotetext{
${ }^{1}$ Some of the results here have previously been circulated as a memo entitled "Emergent International Economic Order." I would like to thanks the participants at Hitotsubashi COE Conference on International Trade and FDI 2009 and Workshop on Economic Growth and Regional Dynamics at Institute of Economic Research, Kyoto University, for their valuable comments.
} 


\section{Introduction}

This paper considers a model of the world economy with a finite number of countries that are (ex-ante) identical. There is a single composite of primary factors and a continuum of tradeable consumption goods, as in the Ricardian model of Dornbusch, Fischer, and Samuelson (1977). Unlike their model, however, productivity of tradeable goods sectors in each country is endogenous and depends on the available variety of local differentiated producer services, which is determined by free entry to the local service sector, as in Dixit and Stiglitz (1977) model of monopolistic competition. The key assumption is that tradeable goods sectors differ in their dependence on local differentiated services. This creates a two-way (i.e., reciprocal) causality between patterns of trade and productivity differences. Having more variety of local services gives a country comparative advantage in tradeable sectors that are more dependent on those services. This in turn means a larger market for those services, hence more firms enter to provide such services. As a result, the country ends up having more variety of local services.

Due to such a circular (or positive feedback) mechanism, any stable equilibrium of the model has the following features. First, different countries sort themselves into specializing in different sets of tradeable goods (endogenous comparative advantage). Second, no two countries share the same level of income or TFP. In other words, a strict ranking of countries in income, TFP, and (in an extension of the model that allows for variable factor supply) capitallabor ratio emerges endogenously. Third, although the model is silent about the ranking of each country (because they are ex-ante identical), it generates a unique distribution across countries (at least with a sufficiently large number of countries).

More specifically, the equilibrium Lorenz curve is fully characterized by a second-order nonlinear difference equation with two terminal conditions. This equation is not analytically solvable. However, as the number of countries increases, this equation converges to a differential equation with a unique solution, which can be solved analytically and depends on a few parameters in a tractable way. This enables us to study, among other things, when crosscountry distribution in income and TFP obeys the power-law and how various forms of globalization affect inequality across countries, and to study the welfare effects of trade.

For example, the model has a set of parameters that represent the degree of differentiation across services, the fraction of the consumption goods that are tradeable, and the share of primary factors of production whose supply can respond to TFP through either factor mobility or 
factor accumulation. With these parameters entering the solution in log-submodular way, it is shown that a change in these parameters causes a Lorenz-dominant shift of the equilibrium Lorenz curve. From this, one could conclude that globalization through trade in goods or trade in factors, or skill-biased technological change that increases the share of human capital and reduces the share of raw labor, etc., leads to greater inequality among countries. It is also shown that, as the number of countries increases, the sufficient and necessary condition under which all countries gain from trade relative to autarky converges to a simple form, which greatly simplifies the task of evaluating the welfare effects of trade. It is also shown that, when this condition fails, there exists a set of tradeable goods such that any countries that end up specializing in these goods would lose from trade, and that a fraction of the countries that end up specializing in such goods can be arbitrarily close to one. Thus, perhaps surprisingly, it is possible that almost all countries may lose from trade, whenever the condition under which some countries lose from trade is met.

Related work: This is a model of symmetry-breaking, a mechanism that generates stable asymmetric equilibria in the symmetric environment due to the instability of the symmetric equilibrium. The idea that symmetry-breaking creates equilibrium variations across ex-ante identical countries, groups, regions, and time has been pursued before. ${ }^{2}$ Indeed, circular mechanisms similar to the one used here play a central role in the so-called new economic geography, e.g., Fujita, Krugman, and Venables (1999) and Combes, Mayer and Thisse (2008), as well as in international trade, e.g., Krugman and Venables (1995) and Matsuyama (1996). These studies have already shown how inequality among ex-ante identical countries/regions arises, but only within highly simplified frameworks, such as two countries/regions and/or two tradeable goods. Such a framework may be too stylized and too qualitative to be taken seriously by many empirical researchers working on cross-country variations in income and TFP. Furthermore, such a stylized framework often comes with highly artificial features. ${ }^{3}$ The present model has advantage of allowing for any finite number of countries and generating a unique

\footnotetext{
${ }^{2}$ For a survey on symmetry-breaking in economics, see a New Palgrave entry by Matsuyama (2008), as well as a related entry on "emergence" by Ioannides (2008).

${ }^{3}$ Take, for example, Matsuyama (1996), a closest precedent to the present paper. It assumes, for the sake of the tractability, two tradeable goods and a continuum of ex-ante identical countries, and shows that there is a continuum of equilibrium distributions, all of which have two clusters of countries. While it achieves the goal of showing how inequality arises among ex-ante identical countries, the prediction that there is a continuum of equilibrium distributions is an artifact of the assumption that there is a continuum of countries and the prediction of two clusters of countries is an artifact of the assumption that there are only two tradeable goods.
} 
equilibrium distribution with quantitative implications. In this respect, Jovanovic $(1998,2009)$ are perhaps closest in spirit to this paper. He shows that the steady state distribution of income across (ex-ante) identical countries obeys a power-law in a model where different vintages of machines need to be assigned to workers with different levels of human capital, which are endogenously chosen by the representative agent in each country. ${ }^{4}$

The rest of the paper is organized as follows. Section 2 studies the basic model, which assumes that all consumption goods are tradeable and all primary factors are in fixed supply. After the key elements of the model are laid out in section 2.1, the unique equilibrium in a single-country world, which may be also viewed as an equilibrium in autarky, is derived in section 2.2. Section 2.3 look at the two-country case, and shows that a symmetric pair of asymmetric stable equilibriums is shown to emerge via symmetry-breaking. Section 2.4 generalizes this to any finite number of countries, by showing endogenous ranking across a finite number of countries, and deriving the difference equation that characterizes the distribution. Section 2.5 studies the limit case, where the number of countries goes to infinity. To the best of my knowledge, the method used to derive the limit differential equation is new in economics and might be of independent interest. With the unique equilibrium distribution in hand, this section looks at power-law examples and shows how log-submodularity helps to prove that a parameter change causes a Lorenz-dominant shift. Section 2.6 conducts the welfare analysis. Section 3 offers two extensions of the basic model. In section 3.1, the fraction of the consumption goods are assumed to be nontradeable. By reducing the fraction, this extension allows us to study the effect of globalization through trade in goods. In section 3.2, one of the primary factors is allowed to vary in supply either through factor mobility and factor accumulation. This extension allows us to study the effect of technological change that increases the relative importance of human capital in production and of globalization through trade in factors on inequality. Section 4 concludes.

\section{Basic Model:}

\subsection{Key Elements of the Model}

\footnotetext{
${ }^{4}$ More broadly, the paper is also related to other studies, such as Acemolgu and Ventura (2002) and Ventura (2005), that point out the need for studying cross-country income differences in a model of the world economy where interactions across countries are explicitly spelled out.
} 
The world consists of $J$ (ex-ante) identical countries, where $J$ is a positive integer. There may be multiple nontradeable primary factors of production, such as capital $(K)$, labor $(L)$, etc., but they can be aggregated to a single composite as $V=F(K, L, \ldots)$. For now, it is assumed that these factors are in fixed supply and that the representative consumer of each country is endowed with the same quantity of the (composite) primary factor, $V$. (Later, one of the component factors is allowed to vary in supply across countries endogenously through factor mobility or factor accumulation.)

As in Dornbusch, Fischer and Samuelson (1977), the representative consumer has CobbDouglas preferences over a continuum of tradeable consumption goods, indexed by $s \in[0,1]$. This can be expressed by an expenditure function, $E=\exp \left[\int_{0}^{1} \beta(s) \log (P(s)) d s\right] U$, where $U$ is utility, $P(s)>0$ the price of good-s, and $\beta(s)>0$ the share of good-s in the expenditure satisfying $\int_{0}^{1} \beta(s) d s=1$. By denoting the aggregate income by $Y$, the budget constraint is then written as

$$
Y=\exp \left[\int_{0}^{1} \beta(s) \log (P(s)) d s\right] U .
$$

The assumption of Cobb-Douglas preferences not only helps to keep the algebra simple but also implies that each good is produced somewhere in the world, which plays an important role in the ensuing analysis.

Each tradeable consumption good is produced competitively with constant returns to scale technology, using nontradeable inputs. They are the (composite) primary factor of production as well as a composite of differentiated local producer services, aggregated by a symmetric CES, as in Dixit and Stiglitz (1977). The primary factor and the composite of local producer services are combined with a Cobb-Douglas technology with $\gamma(s) \in[0,1]$ being the share of local producer services in sector-s. The unit cost of production in each tradeable goods sector can thus be expressed as

$$
C(s)=\zeta(s)(\omega)^{1-\gamma(s)}\left[\int_{0}^{n}(p(z))^{1-\sigma} d z\right]^{\frac{\gamma(s)}{1-\sigma}}=\zeta(s)(\omega)^{1-\gamma(s)}\left[\int_{0}^{n}(p(z))^{1-\sigma} d z\right]^{-\theta \gamma(s)}
$$

with

$$
\sigma=1+\frac{1}{\theta}>1 \Leftrightarrow \theta=\frac{1}{\sigma-1}>0
$$


where $\omega$ is the price of the (composite) primary factor; $n$ the range of differentiated producer services available in equilibrium; $p(z)$ the price of a variety $z \in[0, n]$. The parameter, $\sigma>1$, is the direct partial elasticity of substitution between every pair of local services. It turns out to be notationally more convenient to define $\theta=1 /(\sigma-1)>0$, which I shall call the degree of differentiation. What is crucial here is that the tradeable sectors differ in their dependence on the differentiated local services, $\gamma(s)$. With little loss of generality, $\gamma(s)$ is assumed to be continuous and strictly increasing in $s \in[0,1]$.

Monopolistic competition prevails in the local services sector. Each variety is supplied by a single firm, which uses $T(q)=f+m q$ units of the primary factor to supply $q$ units so that the total cost is $\omega(f+m q)$, of which the fixed cost is $\omega f$ and $\omega m$ represents the marginal cost. As is well-known, each monopolistically competitive firm would set its price equal to $p(z)=(1+\theta) \omega m$ in the standard Dixit-Stiglitz environment. This would mean that it might not be clear whether the effects of shifting $\theta=1 /(\sigma-1)>0$ should be attributed to a change in the degree of differentiation or a change in the mark-up rate. To separate these two conceptually, I depart from the standard Dixit-Stiglitz specification by introducing a competitive fringe. That is, once a firm pays the fixed cost of supplying a particular variety, any other firms could supply its perfect substitute with the marginal cost equal to $(1+v) \omega m>\omega m$ without paying any fixed cost, where $0<v \leq \theta$. The presence of such competitive fringe forces the monopolistically competitive firm to charge a limit price,

$$
p(z)=(1+v) \omega m, \quad \text { where } 0<v \leq \theta .
$$

Note that this pricing rule generalizes the standard Dixit-Stiglitz formulation, as the latter is captured by the special case, $v=\theta$. This generalization is introduced merely to demonstrate that the main results are independent of $v$, when $v<\theta$, so that the effects of $\theta$ should be interpreted as those of changing the degree of differentiation, not the mark-up rate. ${ }^{5}$

From (3), the unit cost of production in each tradeable sector, given by (2), is simplified to:

$$
C(s)=\zeta(s)(\omega)^{1-\gamma(s)}\left\{\int_{0}^{n}[p(z)]^{-\frac{1}{\theta}} d z\right\}^{-\theta \gamma(s)}=\zeta(s)\{(1+v) m\}^{\gamma(s)}(n)^{-\theta \gamma(s)} \omega
$$

\footnotetext{
${ }^{5}$ This generalization of the Dixit-Stiglitz formulation to separate the roles of mark-ups and product differentiation has been used previously. See, e.g., Matsuyama and Takahashi (1998) and Acemoglu (2009, Ch.12.4.4).
} 
Note that, given $\omega$, a higher $n$ reduces the unit cost of production in all tradeable sectors, which is nothing but productivity gains from variety, as discussed by Ethier (1982) and Romer (1987). Eq. (4) shows that this effect is stronger for a larger $\theta$, and that higher-indexed sectors gain more from such variety effect, which plays an important role in the ensuing analysis.

Since all the services are priced equally and enter symmetrically into the production functions, $q(z)=q$ for all $z \in[0, n]$. This implies that the profit of all service providers is given by $\pi(z)=p q-\omega(m q+f)=\omega(v m q-f)$ for all $z \in[0, n]$, from which each service provider earns zero profit if and only if:

$$
v m q=f .
$$

Free entry to (or free exit from) to the local producer services sector ensures that eq.(5) holds in equilibrium.

Before proceeding, we may set

$$
\beta(s)=1 \text { for all } s \in[0,1],
$$

without any further loss of generality, by choosing the tradeable goods indices. ${ }^{6}$ This indexing not only simplifies the notation, but also facilitates the interpretation because it implies that a country's share in the world income is equal to the measure of the tradeable goods for which the country ends up having comparative advantage in equilibrium.

\subsection{Single-Country (or Autarky) Equilibrium $(J=1)$}

First, let us look at the equilibrium allocation for $J=1$. This can be viewed as the case of a one-country world. Alternatively, this can also be viewed as the equilibrium allocation of each country in autarky, which would serve as the benchmark for evaluating the welfare effects of trade in the world economy with multiple countries.

Because of Cobb-Douglas preferences, all the consumption goods must be consumed by positive amounts. Hence, in the absence of trade, the economy must produce all the consumption goods, which means that their prices must be equal to their costs; that is,

\footnotetext{
${ }^{6}$ To see this, starting from any indexing of the goods $s^{\prime} \in[0,1]$ satisfying i) $\tilde{\gamma}\left(s^{\prime}\right)$ is increasing in $s^{\prime} \in[0,1]$, ii) $\widetilde{\beta}\left(s^{\prime}\right)>0$ for all $s^{\prime} \in[0,1]$, and iii) $\int_{0}^{1} \widetilde{\beta}\left(s^{\prime}\right) d s^{\prime}=1$, re-index the goods by a monotone increasing transformation, $s=B\left(s^{\prime}\right) \equiv \int_{0}^{s^{\prime}} \beta(u) d u$. Then, $\gamma(s) \equiv \tilde{\gamma}\left(B^{-1}(s)\right)$ is increasing in $s \in[0,1]$, and $d s=d B\left(s^{\prime}\right)=\beta\left(s^{\prime}\right) d s^{\prime}$, hence $\beta(s)=1$ for all $s \in[0,1]$.
} 


$$
P(s)=C(s)=\zeta(s)\{(1+v) m\}^{\gamma(s)}(n)^{-\theta \gamma(s)} \omega \quad \text { for all } s \in[0,1]
$$

Since the representative consumer spends $\beta(s) Y=Y$ on good-s, and sector-s spends $100 \gamma(s) \%$ of its revenue on producer services, the total revenue of the producer services sector is

$$
n p q=n(1+v) m \omega q=\int_{0}^{1} \gamma(s) \beta(s) Y d s=\Gamma^{A} Y,
$$

where

$$
\Gamma^{A} \equiv \int_{0}^{1} \gamma(s) d s .^{7}
$$

Thus, in autarky, the share of the producer services sector in the aggregate income is equal to the average share of the producer services across all the consumption goods sector. (Here, superscript A stands either for Autarky or for Average).

Likewise, sector-s spends $100(1-\gamma(s)) \%$ of its revenue on the primary factor.

Furthermore, each service provider spends $\omega(f+m q)$ on the primary factor. Therefore, the total income earned by the (composite) primary factor is equal to:

$$
\omega V=\int_{0}^{1}(1-\gamma(s)) \beta(s) Y d s+n \omega(f+m q)=\left(1-\Gamma^{A}\right) Y+n \omega(f+m q) ;
$$

Combining (8) and (10) yields

$$
\frac{Y}{\omega}=\left(\frac{1+1 / v}{1+1 / v-\Gamma^{A}}\right)(V-n f) ; \quad v m q=\left(\frac{\Gamma^{A}}{1+1 / v-\Gamma^{A}}\right)\left(\frac{V}{n}-f\right),
$$

to which we insert the free-entry condition (5) to determine the variety of differentiated services (and the number of service providers) as well as the aggregate income as follows:

$$
\begin{aligned}
n^{A} & =\Gamma^{A}\left(\frac{v}{1+v}\right)\left(\frac{V}{f}\right) \\
Y^{A} & =\omega^{A} V=\omega^{A} F(K, L, \ldots) .
\end{aligned}
$$

Two points about the above equilibrium deserves emphasis. First, as shown in eq. (11), the equilibrium variety of producer services, $n^{A}$, is proportional to the share of producer services

\footnotetext{
${ }^{7}$ It might be useful to explain how the re-indexation discussed in the previous footnote works here. Under a general indexing, $\Gamma^{A} \equiv \int_{0}^{1} \widetilde{\gamma}\left(s^{\prime}\right) \widetilde{\beta}\left(s^{\prime}\right) d s^{\prime}$. With the re-indexing, $s=B\left(s^{\prime}\right) \equiv \int_{0}^{s^{\prime}} \widetilde{\beta}(u) d u$, this can be rewritten as $\Gamma^{A}=\int_{0}^{1} \tilde{\gamma}\left(B^{-1}(s)\right) \beta(s) d s=\int_{0}^{1} \gamma(s) d s$.
} 
in the total expenditure, which is equal to $\Gamma^{A}$ in autarky. Second, free entry ensures zero profit, so that the aggregate income of the economy is accrued entirely to the primary factors, as shown in eq.(12). Because all the primary factors, capital $(K)$, labor $(L)$, etc. can be aggregated into a single composite, $V=F(K, L, \ldots)$, the equilibrium price of the composite factor is nothing but the total factor productivity (TFP) as is commonly measured in the GDP accounting.

\subsection{Two-Country Equilibrium $(J=2)$}

Let us now turn to the trade equilibrium with two ex-ante identical countries, Home and Foreign. Since they are ex-ante identical, they share the same values for all the exogenous parameters. However, endogenous variables, such as $n$ and $\omega$, might take (and in fact will be shown to take) different values, so that asterisks $(*)$ are used to denote Foreign values to distinguish them from Home values.

From (4), the relative cost of production in sector- $s$ is given by:

$$
\frac{C(s)}{C^{*}(s)}=\left(\frac{n}{n^{*}}\right)^{-\theta \gamma(s)}\left(\frac{\omega}{\omega^{*}}\right),
$$

which is increasing in $s$ if $n<n^{*}$; decreasing in $s$ if $n>n^{*}$; and independent of $s$ if $n=n^{*}$. This shows the patterns of comparative advantage. The country with a more developed local support industry has comparative advantage in higher-indexed sectors, which rely more heavily on local producer services. However, unlike the standard neoclassical theory of trade, the source of comparative advantage is endogenous here because $n$ and $n^{*}$ are endogenous.

To solve for an equilibrium allocation, suppose $n<n^{*}$ for the moment, hence the graph of $C(s) / C^{*}(s)$ is upward-sloping, as shown in Figure 1. The height of this graph depends on $\omega / \omega^{*}$, the relative factor prices. If $\omega / \omega^{*}$ were so high to make the graph of $C(s) / C^{*}(s)$ lie everywhere above one, Home would import all the goods from Foreign, while exporting none; this cannot be an equilibrium. Similarly, $\omega / \omega^{*}$ cannot be so low to make the graph of $C(s) / C^{*}(s)$ lie everywhere below one. Thus, in equilibrium, Home produces and exports $s \in[0, S)$ \& Foreign produces and exports $s \in(S, 1]$, where $S \in(0,1)$ is defined by

$$
\frac{C(S)}{C^{*}(S)}=\left(\frac{n}{n^{*}}\right)^{-\theta \gamma(S)}\left(\frac{\omega}{\omega^{*}}\right)=1,
$$


as shown in Figure 1. ${ }^{8}$ This means that the equilibrium factor prices can be expressed as

$$
\frac{\omega}{\omega^{*}}=\left(\frac{n}{n^{*}}\right)^{\theta \gamma(S)}<1 .
$$

Thus, due to the productivity effect of more variety $\left(n<n^{*}\right)$, the factor price is higher at Foreign than at Home $\left(\omega<\omega^{*}\right)$.

Because of Cobb-Douglas preferences, the total revenue of Home sector- $s \in[0, S)$ is equal to $\beta(s)\left(Y+Y^{*}\right)=Y+Y^{*}$, of which $100 \gamma(s) \%$ goes to the Home producer services. Thus, by adding up across all sectors in $[0, S)$, the total revenue of the Home producer services sector is

$$
n p q=n(1+v) m \omega q=\left[\int_{0}^{S} \gamma(s) d s\right]\left(Y+Y^{*}\right)=\Gamma^{-}(S) S\left(Y+Y^{*}\right),
$$

where

$$
\Gamma^{-}(S) \equiv \frac{1}{S} \int_{0}^{S} \gamma(s) d s
$$

is the average share of producer services across all tradeable sectors in $[0, S)$. Clearly, it is increasing in $S$ with $\Gamma^{-}(0)=\gamma(0)<\Gamma^{-}(1)=\Gamma^{A}$.

Likewise, for each $s \in[0, S)$, Home sector-s spends $100(1-\gamma(s)) \%$ of its revenue on the Home primary factor. Furthermore, each Home service provider spends $\omega(f+m q)$ on the Home primary factor. Therefore, the total income earned by the Home (composite) primary factor is equal to:

$$
\omega V=\left(1-\Gamma^{-}(S)\right) S\left(Y+Y^{*}\right)+n \omega(m q+f)
$$

Combining (14) and (16) yields

$$
\frac{S\left(Y+Y^{*}\right)}{\omega}=\left(\frac{1+1 / v}{1+1 / v-\Gamma^{-}(S)}\right)(V-n f) ; \quad v m q=\left(\frac{\Gamma^{-}(S)}{1+1 / v-\Gamma^{-}(S)}\right)\left(\frac{V}{n}-f\right),
$$

to which we insert the free entry condition (5) to obtain:

$$
\begin{aligned}
& n=\Gamma^{-}(S)\left(\frac{v}{1+v}\right)\left(\frac{V}{f}\right) ; \\
& Y=S\left(Y+Y^{*}\right)=\omega V=\omega F(K, L \ldots) .
\end{aligned}
$$

\footnotetext{
${ }^{8}$ The borderline sector, $S$, can be produced in either country and its trade flow is indeterminate. This type of indeterminacy is inconsequential, and hence ignored in the following discussion.
} 
Thus, the equilibrium variety of Home local services is proportional to $\Gamma^{-}(S)<\Gamma^{A}$; $S$ represents Home's share in the world income and $\omega$ Home's TFP.

Likewise, one could follow the same steps for Foreign sector- $s \in(S, 1]$ to obtain

$$
\begin{aligned}
& n^{*}=\Gamma^{+}(S)\left(\frac{v}{1+v}\right)\left(\frac{V}{f}\right) ; \\
& Y^{*}=(1-S)\left(Y+Y^{*}\right)=\omega^{*} V==\omega^{*} F(K, L \ldots) .
\end{aligned}
$$

where

$$
\Gamma^{+}(S) \equiv \frac{1}{1-S} \int_{S}^{1} \gamma(s) .
$$

is the average share of producer services across all the tradeable sectors in $(S, 1]$, which is increasing in $S$ with $\Gamma^{+}(0)=\Gamma^{A}<\Gamma^{+}(1)=\gamma(1)$. In particular, for any $S \in(0,1)$,

$$
\Gamma^{-}(S)<\Gamma^{A}<\Gamma^{+}(S),
$$

which in turn implies, from (11), (17) and (19), $n<n^{A}<n^{*}$. Thus, our initial supposition that $n$ $<n^{*}$ hold in equilibrium has now been verified. Furthermore, from (18) and (20),

$$
\frac{Y}{Y^{*}}=\frac{\omega}{\omega^{*}}=\frac{S}{1-S}<1
$$

so that the distribution is fully characterized by $S$, which, from (13) and (22) satisfies

$$
\frac{S}{1-S}=\left(\frac{\Gamma^{-}(S)}{\Gamma^{+}(S)}\right)^{\theta \gamma(S)}<1 .
$$

In summary, this demonstrates the existence of an equilibrium, where Home produces and exports $s \in[0, S)$ and Foreign produces and exports $s \in(S, 1]$, where $S$ represents the Home share in both income and TFP, given by a solution to eq. (23).

Recall that we began the analysis by supposing $n<n^{*}$ to obtain the above equilibrium. By supposing $n>n *$ instead, we can obtain another equilibrium, which is the mirror-image of the above equilibrium, where the positions of the two countries are reversed.

The intuition behind the existence of such a symmetric pair of asymmetric equilibriums is a two-way causality between the patterns of trade and comparative advantage. A country with a more developed local services sector has comparative advantage in tradeable sectors that depend more on local services. And a country with a comparative advantage in those sectors has a more developed local services sector. Since these two equilibriums are the mirror-images of each 
other; they both predict the same equilibrium distribution of income and of TFP in the world economy, summarized by $S$, a solution to eq. (23). ${ }^{9}$

Indeed, there is another equilibrium, where $n=n^{*}=n^{A}$. In this symmetric equilibrium, which replicates the autarky equilibrium in each country, the unit cost of production of each tradeable good is equal across two countries, so that the consumers everywhere is indifferent as to which country they purchase tradeable goods from. In other words, the patterns of trade are indeterminate in this case. If exactly $50 \%$ of the world income is spent on each country's tradeable goods sectors, and if these spending is distributed across the two countries in such a way that the local services sector of each country ends up receiving exactly $\Gamma^{A} / 2$ fraction of the world spending, then free entry to this sector in each country would lead to $n=n^{*}=n^{A}$. However, it is easy to see that this equilibrium is fragile in that the required spending patterns described above must be exactly met in spite that the consumers are indifferent. Furthermore, this equilibrium is unstable in that a small perturbation that causes $n>n^{*}\left(n<n^{*}\right)$ would lead to an abrupt change in the spending patterns that makes the profit of Home local service firms rise (fall) discontinuously, which leads to a higher (lower) $n$ and the profit of Foreign local service firms fall (rise) discontinuously, which leads to a lower (higher) $n^{*}$.

The mechanism that causes the instability of the symmetric equilibrium, $n=n^{*}=n^{A}$, is indeed the same two-way causality that generates the symmetric pair of stable asymmetric equilibriums demonstrated above. Although such a symmetry-breaking mechanism is wellknown in the literature on international trade and economic geography, they are usually demonstrated in models of two countries or regions. One of the advantages of the present model is that it can be extended to any finite number of countries.

\subsection{Multi-Country Equilibrium $(2<J<\infty)$}

Note first that the same logic behind the instability of the symmetric equilibrium in the two-country world implies that no two countries share the same value of $n$ in any stable equilibrium. The countries can be thus ranked in such a way that $\left\{n_{j}\right\}_{j=1}^{J}$ is a monotone increasing sequence. (Here, subscripts indicate the positions of countries in a particular

\footnotetext{
${ }^{9}$ Although I have been unable to find an example, eq.(23) might have multiple solutions for some $\gamma$ functions. If this is the case, there is a symmetric pair of asymmetric stable equilibriums for each solution to eq. (23). However, I am not concerned about the possibility of this kind of multiplicity, as it can be ruled out for a sufficiently large $J$, as will be seen below.
} 
equilibrium, not the identity of the country.) Then, from (4), the relative cost between the $j$-th and the $(j+1)$-th countries,

$$
\frac{C_{j}(s)}{C_{j+1}(s)}=\left(\frac{n_{j}}{n_{j+1}}\right)^{-\theta \gamma(s)}\left(\frac{\omega_{j}}{\omega_{j+1}}\right)
$$

is strictly increasing in $s$ for any $j=1,2, \ldots, J-1$, for any combination of the factor prices $\left\{\omega_{j}\right\}_{j=1}^{J}$. In equilibrium, $\left\{\omega_{j}\right\}_{j=1}^{J}$ must adjust such that each country becomes the strictly lowest cost producers and hence the exporter for a positive measure of the tradeable goods. This condition implies that a sequence, $\left\{S_{j}\right\}_{j=0}^{J}$, defined by

$$
S_{0}=0, S_{J}=1 \text {, }
$$

and

$$
\frac{C_{j}\left(S_{j}\right)}{C_{j+1}\left(S_{j}\right)}=\left(\frac{n_{j}}{n_{j+1}}\right)^{-\theta \gamma\left(S_{j}\right)}\left(\frac{\omega_{j}}{\omega_{j+1}}\right)=1 \quad(j=1,2, \ldots, J-1),
$$

is monotone increasing. ${ }^{10}$ This is illustrated in Figure 2, which also implies that the patterns of trade are such that the set of the tradeable goods, [0,1], is partitioned into $J$ intervals of $\left(S_{j-1}, S_{j}\right)$ $(j=1,2, \ldots, J)$, and the $j$-th country produces and exports $s \in\left(S_{j-1}, S_{j}\right){ }^{11}$ Furthermore, the definition of $\left\{S_{j}\right\}_{j=1}^{J-1}$ can be rewritten to obtain:

$$
\frac{\omega_{j+1}}{\omega_{j}}=\left(\frac{n_{j+1}}{n_{j}}\right)^{\theta \gamma\left(S_{j}\right)}>1 . \quad(j=1,2, \ldots, J-1)
$$

Hence, $\left\{\omega_{j}\right\}_{j=1}^{J}$ is also monotone increasing.

Since the $j$-th country specializes in $\left(S_{j-1}, S_{j}\right), 100\left(S_{j}-S_{j-1}\right) \%$ of the world income, $Y^{W}$, is spent on its tradeable sectors, and its sector-s in $\left(S_{j-1}, S_{j}\right)$ spends $100 \gamma(s) \%$ of its revenue on its local services. Thus, the total revenues of its local producer services sector is equal to

$$
n_{j} p_{j} q_{j}=n_{j}(1+v) m \omega_{j} q_{j}=\left[\int_{S_{j-1}}^{S_{j}} \gamma(s) d s\right] Y^{W}=\left(S_{j}-S_{j-1}\right) \Gamma_{j} Y^{W}, \quad(j=1,2, \ldots, J)
$$

\footnotetext{
${ }^{10}$ To see why, $S_{j} \geq S_{j+1}$ would imply $C_{j}(s)>\min \left\{C_{j-1}(s), C_{j+1}(s)\right\}$ for all $s \in[0,1]$, hence that the $j$-th country is not the lowest cost producers of any tradeable good, a contradiction.

${ }^{11}$ In addition, $S_{0}$ is produced and exported by the $1^{\text {st }}$ country and $S_{J}$ by the $J$-th country. For $S_{j}(j=1,2, \ldots, J-1)$, it could be produced by either $j$-th or $(j+1)$-th country, and its patterns of trade are indeterminate. Again, this type of indeterminacy is inconsequential and ignored in the following discussion.
} 
where

$$
\Gamma_{j} \equiv \Gamma\left(S_{j-1}, S_{j}\right) \equiv \frac{1}{S_{j}-S_{j-1}} \int_{S_{j-1}}^{S_{j}} \gamma(s) d s . \quad(j=1,2, \ldots, J)
$$

is the average share of producer services across all tradeable sectors in $\left(S_{j-1}, S_{j}\right)$. Since $\gamma(\bullet)$ is increasing, $\left\{\Gamma_{j}\right\}_{j=1}^{J}$ is also monotone increasing.

Likewise, in the $j$-th country, sector- $s \in\left(S_{j-1}, S_{j}\right)$ spends $100(1-\gamma(s)) \%$ of its revenue on its primary factor, and each service provider spends $\omega_{j}\left(f+m q_{j}\right)$ on its primary factor. Thus, the total income earned by the primary factor in the $j$-th country is equal to:

$$
\omega_{j} V=\left(1-\Gamma_{j}\right)\left(S_{j}-S_{j-1}\right) Y^{W}+n_{j} \omega_{j}\left(m q_{j}+f\right) \quad(j=1,2, \ldots, J)
$$

Combining (25) and (27) yields:

$$
\frac{\left(S_{j}-S_{j-1}\right) Y^{W}}{\omega_{j}}=\left(\frac{1+1 / v}{1+1 / v-\Gamma_{j}}\right)\left(V-n_{j} f\right) ; v m q_{j}=\left(\frac{\Gamma_{j}}{1+1 / v-\Gamma_{j}}\right)\left(\frac{V}{n_{j}}-f\right) \quad(j=1,2, \ldots, J)
$$

to which we insert the free-entry, zero profit condition (5) to yield

$$
n_{j}=\Gamma_{j}\left(\frac{v}{(1+v)}\right)\left(\frac{V}{f}\right) ; \quad(j=1,2, \ldots, J)
$$

and

$$
Y_{j}=\omega_{j} V=\left(S_{j}-S_{j-1}\right) Y^{W} . \quad(j=1,2, \ldots, J)
$$

Because $\left\{\Gamma_{j}\right\}_{j=1}^{J}$ is monotone increasing, eq.(28) shows that $\left\{n_{j}\right\}_{j=1}^{J}$ is also monotone increasing, as has been assumed. Eq.(29) shows that $\omega_{j}$ represents TFP of the $j$-th poorest country, and $s_{j} \equiv S_{j}-S_{j-1}$, the measure of the tradeable goods in which this country has comparative advantage, is also equal to its share in the world income. It also implies that $S_{j}=\sum_{k=1}^{j} s_{k}$ represents the share of the $j$ poorest countries in world income.

Finally, by combining (24), (28), and (29), we obtain the equation that determines $\left\{S_{j}\right\}_{j=0}^{J}$ that characterizes the distribution of income (as well as of TFPs) across countries:

$$
\frac{S_{j+1}-S_{j}}{S_{j}-S_{j-1}}=\left(\frac{\Gamma\left(S_{j}, S_{j+1}\right)}{\Gamma\left(S_{j-1}, S_{j}\right)}\right)^{\theta_{\gamma}\left(S_{j}\right)}>1 \text { with } S_{0}=0 \text { and } S_{J}=1
$$

To summarize; 
Proposition 1: Let $S_{j}$ be the share of the $j$ poorest countries in world income. Then, $\left\{S_{j}\right\}_{j=0}^{J}$ is a solution to the nonlinear $2^{\text {nd }}$-order difference equation with the two terminal conditions:

$$
\frac{S_{j+1}-S_{j}}{S_{j}-S_{j-1}}=\left(\frac{\Gamma\left(S_{j}, S_{j+1}\right)}{\Gamma\left(S_{j-1}, S_{j}\right)}\right)^{\theta \gamma\left(S_{j}\right)}>1 \text { with } S_{0}=0 \& S_{J}=1,
$$

where $\Gamma\left(S_{j-1}, S_{j}\right) \equiv \frac{1}{S_{j}-S_{j-1}} \int_{S_{j-1}}^{S_{j}} \gamma(s) d s$.

Figure 3 illustrates a solution to eq.(30) graphically by means of the Lorenz curve, $\Phi^{J}:[0,1] \rightarrow[0,1]$, defined by the piece-wise linear function, satisfying $\Phi^{J}(j / J)=S_{j}$. From this Lorenz curve, we can easily recover $\left\{s_{j}\right\}_{j=0}^{J}$, the distribution of the country shares in the world income and vice versa. ${ }^{12}$ A few points deserve emphasis. First, because $\Gamma\left(S_{j-1}, S_{j}\right)$ is increasing in $j, s_{j+1} / s_{j} \equiv\left(S_{j+1}-S_{j}\right) /\left(S_{j}-S_{j-1}\right)$ is increasing in $j$. Hence, the Lorenz curve is kinked at $j / J$ for each $j=1,2, \ldots, J-1$. In other words, the ranking of the countries is strict. ${ }^{13}$ Second, since both income and TFP are proportional to $s_{j} \equiv S_{j}-S_{j-1}$, the Lorenz curve here also represents the Lorenz curve for income and TFP. Third, we could also obtain the ranking of countries in other variables of interest that are functions of $\left\{s_{j}\right\}_{j=0}^{J}$. For example, the $j$-th country's share in world trade can be shown to be equal to $\left\{s_{j}-\left(s_{j}\right)^{2}\right\} / \sum_{k=1}^{J}\left\{s_{k}-\left(s_{k}\right)^{2}\right\}$, which is increasing in $j$. The $j$-th country's trade dependence, defined by the volume of trade divided by its GDP, can be shown to be equal to $1-s_{j}$, which is decreasing in $j$.

Even though the nonlinear difference equation, eq. (30), fully characterizes the equilibrium distribution across countries, it is not analytically solvable. Of course, one could try to solve it numerically. However, numerical methods are not useful for answering the question

\footnotetext{
${ }^{12}$ This merely states that there is a one-to-one correspondence between the distribution of income and the Lorenz curve. With $J$ ex-ante identical countries, there are $J$ ! (factorial) equilibria for each Lorenz curve. Furthermore, there may be multiple solutions to (30), although such multiplicity can be ruled out for a sufficiently large $J$, as will be seen below.

${ }^{13}$ This is in sharp contract to the model of Matsuyama (1996), which generates a non-degenerate distribution of income across countries, but with a clustering of countries that share the same level of income. The crucial difference seems that there are more countries than tradeable goods in the model of Matsuyama (1996), while the tradeable goods outnumbers the countries in the present model.
} 
of the uniqueness or for determining how the solution depends on the parameters of the model. Instead, in spirit similar to the central limit theorem, let us to approximate the equilibrium Lorenz curve by $\lim _{J \rightarrow \infty} \Phi^{J}=\Phi$. It turns out that, as $J \rightarrow \infty$, eq.(30) converges to the nonlinear $2^{\text {nd }}$-order differential equation with a unique solution that can be solved analytically. This allows us to study not only the effects of changing the parameters on the Lorenz curve, but also the welfare effects of trade.

\subsection{Equilibrium Lorenz Curve: Limit Case $(J \rightarrow \infty)$}

I will now sketch the method to obtain the limit Lorenz curve, $\lim _{J \rightarrow \infty} \Phi^{J}=\Phi$. Although the method is technical in nature, it is worthwhile partly because the method will be used again in extensions of the model, and partly because it might be potentially useful for other applications in economics. The basic strategy is to take Taylor expansions on both sides of eq. $(30) .^{14}$

First, by setting $x=j / J$ and $\Delta x=1 / J$,

$$
\begin{aligned}
& S_{j+1}-S_{j}=\Phi(x+\Delta x)-\Phi(x)=\Phi^{\prime}(x) \Delta x+\Phi^{\prime \prime}(x) \frac{|\Delta x|^{2}}{2}+o\left(|\Delta x|^{2}\right), \\
& S_{j}-S_{j-1}=\Phi(x)-\Phi(x-\Delta x)=\Phi^{\prime}(x) \Delta x-\Phi^{\prime \prime}(x) \frac{|\Delta x|^{2}}{2}+o\left(|\Delta x|^{2}\right),
\end{aligned}
$$

from which the LHS of eq. (30) can be written as:

$$
\frac{S_{j+1}-S_{j}}{S_{j}-S_{j-1}}=1+\frac{\Phi^{\prime \prime}(x)}{\Phi^{\prime}(x)} \Delta x+o(|\Delta x|) .
$$

Likewise,

$$
\begin{gathered}
\Gamma\left(S_{j}, S_{j+1}\right)=\frac{\int_{\Phi(x)}^{\Phi(x+\Delta x)} \gamma(s) d s}{\Phi(x+\Delta x)-\Phi(x)}=\gamma(\Phi(x))+\frac{1}{2} \gamma^{\prime}(\Phi(x)) \Phi^{\prime}(x) \Delta x+o(|\Delta x|) \\
\Gamma\left(S_{j}, S_{j-1}\right)=\frac{\int_{\Phi(x-\Delta x)}^{\Phi(x)} \gamma(s) d s}{\Phi(x)-\Phi(x-\Delta x)}=\gamma(\Phi(x))-\frac{1}{2} \gamma^{\prime}(\Phi(x)) \Phi^{\prime}(x) \Delta x+o(|\Delta x|)
\end{gathered}
$$

from which the RHS of eq.(30) can be written as:

\footnotetext{
${ }^{14}$ Initially, I obtained the (correct) limit Lorenz curve by a different method, which involves repeated use of the mean value theorem. However, Hiroshi Matano, a mathematician and an expert in this area, pointed out to me that it is not rigorous and instead showed me the right method, to which I am grateful.
} 


$$
\begin{aligned}
& \left(\frac{\Gamma\left(S_{j}, S_{j+1}\right)}{\Gamma\left(S_{j-1}, S_{j}\right)}\right)^{\theta \gamma\left(S_{j}\right)}=\left(1+\frac{\gamma^{\prime}(\Phi(x))}{\gamma(\Phi(x))} \Phi^{\prime}(x) \Delta x+o(|\Delta x|)\right)^{\theta \gamma(\Phi(x))} \\
& =1+\theta \gamma^{\prime}(\Phi(x)) \Phi^{\prime}(x) \Delta x+o(|\Delta x|) .
\end{aligned}
$$

By combining these, eq.(30) becomes:

$$
1+\frac{\Phi^{\prime \prime}(x)}{\Phi^{\prime}(x)} \Delta x+o(|\Delta x|)=1+\theta \gamma^{\prime}(\Phi(x)) \Phi^{\prime}(x) \Delta x+o(|\Delta x|) .
$$

By letting $\Delta x=1 / J \rightarrow 0$, eq.(30) converges to the following differential equation:

$$
\frac{\Phi^{\prime \prime}(x)}{\Phi^{\prime}(x)}=\theta \gamma^{\prime}(\Phi(x)) \Phi^{\prime}(x)
$$

To solve it, integrate it once to obtain

$$
\log \left(\Phi^{\prime}(x)\right)-\theta \gamma(\Phi(x))=c_{0} \quad \text { or } \quad \exp (-\theta \gamma(\Phi(x))) \Phi^{\prime}(x)=e^{c_{0}}
$$

where $c_{0}$ is a constant to be determined. By integrating the above once again,

$$
\int_{0}^{\Phi(x)} e^{-\theta \gamma(s)} d s=c_{1}+e^{c_{0}} x
$$

where $c_{1}$ is another constant to be determined. From the two terminal conditions, $\Phi(0)=0$ and $\Phi(1)=1$,

$$
c_{1}=\int_{0}^{0} e^{-\theta \gamma(s)} d s=0 ; \quad e^{c_{0}}=\int_{0}^{1} e^{-\theta \gamma(s)} d s ;
$$

from which the solution, $\Phi:[0,1] \rightarrow[0,1]$, is determined uniquely by

$$
\int_{0}^{\Phi(x)} e^{-\theta \gamma(s)} d s=\left[\int_{0}^{1} e^{-\theta \gamma(u)} d u\right] x
$$

which can be rewritten more compactly as:

$$
x=H(\Phi(x)) \equiv \int_{0}^{\Phi(x)} h(s) d s, \quad \text { where } h(s) \equiv \frac{e^{-\theta \gamma(s)}}{\int_{0}^{1} e^{-\theta \gamma(u)} d u} .
$$

To summarize:

Proposition 2: The limit equilibrium Lorenz curve, $\lim _{J \rightarrow \infty} \Phi^{J}=\Phi$, is characterized by the nonlinear $2^{\text {nd }}$-order differential equation with the two terminal conditions: 


$$
\frac{\Phi^{\prime \prime}(x)}{\Phi^{\prime}(x)}=\theta \gamma^{\prime}(\Phi(x)) \Phi^{\prime}(x) \text { with } \Phi(0)=0 \text { and } \Phi(1)=1
$$

whose unique solution is given by:

$$
x=H(\Phi(x)) \equiv \int_{0}^{\Phi(x)} h(s) d s, \text { where } h(s) \equiv \frac{e^{-\theta_{\gamma}(s)}}{\int_{0}^{1} e^{-\theta_{\gamma}(u)} d u} .
$$

Figure 4 illustrates the unique solution, (32). As shown in the left panel, $h(s)$ is positive and decreasing in $s \in[0,1]$. Thus, its integral, $x=H(s)$, is increasing and concave. Furthermore, $h(s)$ is normalized in such a way that $H(0)=0$ and $H(1)=1$, as shown in the right panel.

Hence, its inverse function, the Lorenz curve, $s=\Phi(x)=H^{-1}(x)$ is increasing, convex, with $\Phi(0)=0$ and $\Phi(1)=1$.

With the limit Lorenz curve $s=\Phi(x)=H^{-1}(x)$ in hand, one could easily calculate:

- Share of Country at $100 x \%$ in World GDP: $\Phi^{\prime}(x) d x=\left[\int_{0}^{1} e^{-\theta_{\gamma}(s)} d s\right] e^{\theta_{\gamma}(\Phi(x))} d x$.

- GDP of Country at $100 x \%$ (with World GDP normalized to one):

$$
y=\Phi^{\prime}(x)=\left[\int_{0}^{1} e^{-\theta_{\gamma}(s)} d s\right] e^{\theta_{\gamma}(\Phi(x))}
$$

- Ratio of the richest to the poorest: $\frac{y_{\text {Max }}}{y_{\text {Min }}}=\frac{\Phi^{\prime}(1)}{\Phi^{\prime}(0)}=\frac{H^{\prime}(0)}{H^{\prime}(1)}=\frac{h(0)}{h(1)}=e^{\theta(\gamma(1)-\gamma(0))} \leq e^{\theta}$.

Furthermore, the cumulative distribution function (cdf) of (normalized) GDPs, $y$, can be readily calculated as $x=\Psi(y) \equiv\left(\Phi^{\prime}\right)^{-1}(y)$. The following table illustrates the calculation by using power-law (e.g., truncated Pareto) examples.

Table: Power-Law Examples

\begin{tabular}{|l|c|c|c|}
\hline & $\begin{array}{c}\text { Example 1: } \\
\gamma(s)=s\end{array}$ & $\begin{array}{c}\text { Example 2: } \\
\gamma(s)=\log \left[1+\left(e^{\theta}-1\right) s\right]^{\frac{1}{\theta}}\end{array}$ & $\begin{array}{c}\text { Example 3: } \\
\gamma(s)=\log \left[1+\left(e^{\lambda}-1\right) s\right]^{\frac{1}{\lambda}} ;(\lambda \neq 0 ; \neq \theta)\end{array}$ \\
\hline $\begin{array}{l}\text { Inverse } \\
\text { Lorenz } \\
\text { Curve }\end{array}$ & $\frac{1-e^{-\theta s}}{1-e^{-\theta}}$ & $\log \left[1+\left(e^{\theta}-1\right) s\right]^{\frac{1}{\theta}}$ & $\frac{\left[1+\left(e^{\lambda}-1\right) s\right]^{1-\frac{\theta}{\lambda}}-1}{e^{\lambda-\theta}-1}$ \\
\hline
\end{tabular}




\begin{tabular}{|l|c|c|c|}
\hline \multicolumn{1}{|c|}{$x=H(s)$} & & $\frac{e^{\theta x}-1}{e^{\theta}-1}$ & $\frac{\left[1+\left(e^{\lambda-\theta}-1\right) x\right]^{\lambda-\theta}-1}{e^{\lambda}-1}$ \\
\hline $\begin{array}{l}\text { Lorenz } \\
\text { Curve: } \\
s=\Phi(x) \\
=H^{-1}(x)\end{array}$ & $\log \left[1-\left(1-e^{-\theta}\right) x\right]^{-\frac{1}{\theta}}$ & $\frac{1}{\theta} \log \left(\frac{e^{\theta}-1}{\theta} y\right)$ & $\frac{\left(\frac{y}{y_{\text {Min }}}\right)^{\frac{\lambda}{\theta}-1}-1}{e^{\lambda-\theta}-1}=1-\frac{1-\left(\frac{y}{y_{\text {Max }}}\right)^{\frac{\lambda}{\theta}-1}}{1-e^{\theta-\lambda}}$ \\
\hline $\begin{array}{l}\text { Cdf: } \\
x=\Psi(y) \\
=\left(\Phi^{\prime}\right)^{-1}(y)\end{array}$ & $\frac{1}{1-e^{-\theta}}-\frac{1}{\theta y}$ & $\frac{1}{\theta y}$ & {$\left[\frac{(\lambda / \theta)-1}{\left(y_{\text {Max }}\right)^{(\lambda / \theta)-1}-\left(y_{\text {Min }}\right)^{(\lambda / \theta)-1}}\right](y)^{\frac{\lambda}{\theta}-2}$} \\
\hline $\begin{array}{l}\text { Pdf: } \\
\psi(y) \\
=\Psi '(y)\end{array}$ & $\frac{1}{\theta y^{2}}$ & $\frac{\theta}{\Psi^{\theta}-1} \leq y \leq \frac{\theta e^{\theta}}{e^{\theta}-1}$ & $\left(\frac{\lambda}{e^{\lambda}-1}\right)\left(\frac{e^{\lambda-\theta}-1}{\lambda-\theta}\right) \leq y \leq\left(\frac{\lambda}{e^{\lambda}-1}\right)\left(\frac{e^{\lambda-\theta}-1}{\lambda-\theta}\right) e^{\theta}$ \\
\hline $\begin{array}{l}\text { Support } \\
{\left[y_{\text {Min }}, y_{\text {Max }}\right]}\end{array}$ & $\frac{1-e^{-\theta}}{\theta} \leq y \leq \frac{e^{\theta}-1}{\theta}$ & \\
\hline
\end{tabular}

Note that Example 1 and Example 2 may be viewed as the limit cases of Example 3, as $\lambda \rightarrow 0$ and $\lambda \rightarrow \theta$, respectively. As $\lambda$ varies from $-\infty$ to $+\infty$, the "power" in the probability density function (pdf), $\lambda / \theta-2$, changes from $-\infty$ to $+\infty$. As $\lambda \rightarrow-\infty$, the use of the local services become more concentrated in a narrow range of tradeable sectors, which means that just a small fraction of countries specialize in such "desirable" tradeable goods. Thus, the pdf declines sharply in the upper end.

Another advantage of the limit Lorenz curve, (32), is that one could easily see the effect of changing $\theta$, which is illustrated in Figure 4. To see this, note first that $\hat{h}(s) \equiv e^{-\theta \gamma(s)}$, the numerator of $h(s)$, satisfies

$$
\frac{\partial^{2} \log (\hat{h}(s))}{\partial \theta \partial s}=-\gamma^{\prime}(s)<0 .
$$

In words, it is log-submodular in $\theta$ and $s .{ }^{15}$ Thus, a higher $\theta$ shifts the graph of $\hat{h}(s) \equiv e^{-\theta \gamma(s)}$ down everywhere but proportionately more at a higher $s$. Since $h(s)$ is a rescaled version of $\hat{h}(s)$ to keep the area under the graph unchanged, the graph of $h(s)$ is rotated "clockwise" by a higher $\theta$, as shown in the left panel. This "single-crossing" in $h(s)$ implies that a higher $\theta$ makes the Lorenz curve more "curved" and move further away from the diagonal line, as shown in the

\footnotetext{
${ }^{15}$ See Topkis (1998) for mathematics of super- and sub-modularity and Costinot (2009) for a recent application to international trade.
} 
right panel. In other words, a higher $\theta$ causes a Lorenz-dominant shift of the Lorenz curve. Thus, any Lorenz-consistent inequality measure, such as the generalized Kuznets Ratio, the Gini index, the coefficients of variations, etc. all agree that a higher $\theta$ leads to greater inequality. ${ }^{16}$

\subsection{Welfare Effects of Trade}

Let us turn to the welfare effects of trade. The mere fact that international trade creates ranking of countries and makes some countries poorer than others, does not necessarily imply that trade make them poorer. We need to compare the utility levels under trade and under autarky.

From eq.(1), the welfare under autarky is

$$
\log \left(U^{A}\right)=\log \left(\omega^{A} V\right)-\int_{0}^{1} \log \left(P^{A}(s)\right) d s .
$$

Likewise, the welfare of the country that ends up being the $j$-th poorest can be written as:

$$
\log \left(U_{j}\right)=\log \left(\omega_{j} V\right)-\int_{0}^{1} \log (P(s)) d s
$$

where the tradeable goods prices satisfy

$$
\frac{P(s)}{P^{A}(s)}=\left(\frac{\omega_{k}}{\omega^{A}}\right)\left(\frac{n_{k}}{n^{A}}\right)^{-\theta \gamma(s)}=\left(\frac{\omega_{k}}{\omega^{A}}\right)\left(\frac{\Gamma_{k}}{\Gamma^{A}}\right)^{-\theta \gamma(s)} \text { for } s \in\left(S_{k-1}, S_{k}\right) \text { for } k=1,2, \ldots, J .
$$

Combining these equations yields

$$
\log \left(\frac{U_{j}}{U^{A}}\right)=\log \left(\frac{\omega_{j}}{\omega^{A}}\right)-\int_{0}^{1} \log \left(\frac{P(s)}{P^{A}(s)}\right) d s=\log \left(\frac{\omega_{j}}{\omega^{A}}\right)-\sum_{k=1}^{J}\left[\int_{S_{k-1}}^{S_{k}} \log \left(\frac{\omega_{k}}{\omega^{A}}\right) d s-\int_{S_{k-1}}^{S_{k}} \theta \gamma(s) \log \left(\frac{\Gamma_{k}}{\Gamma^{A}}\right) d s\right],
$$

which can be further rewritten as follows:

Proposition 3 (J-country case): The country that ends up being the $j$-th poorest under trade gains from trade if and only if:

$$
\log \left(\frac{U_{j}}{U^{A}}\right)=\sum_{k=1}^{J} \log \left(\frac{\omega_{j}}{\omega_{k}}\right)\left(S_{k}-S_{k-1}\right)+\theta \sum_{k=1}^{J} \Gamma_{k} \log \left(\frac{\Gamma_{k}}{\Gamma^{A}}\right)\left(S_{k}-S_{k-1}\right)>0 .
$$

Proposition 3 offers a decomposition of the welfare effects of trade. The first term of eq.(33)

\footnotetext{
${ }^{16}$ Likewise, any shift in $\gamma(s)$ that rotates $h(s)$ clockwise leads to greater inequality.
} 


$$
\sum_{k=1}^{J} \log \left(\frac{\omega_{j}}{\omega_{k}}\right)\left(S_{k}-S_{k-1}\right)=\log \left(\omega_{j} / \prod_{k=1}^{J}\left(\omega_{k}\right)^{\left(S_{k}-S_{k-1}\right)}\right)=\log \left(Y_{j} / \prod_{k=1}^{J}\left(Y_{k}\right)^{\left(S_{k}-S_{k-1}\right)}\right)
$$

represents the country's income (as well as TFP) relative to the world average. This term is monotone increasing in $j$, negative at $j=1$ and positive at $j=J$. The second term of (33),

$$
\theta \sum_{k=1}^{J} \Gamma_{k} \log \left(\frac{\Gamma_{k}}{\Gamma^{A}}\right)\left(S_{k}-S_{k-1}\right)>0
$$

captures the usual gains from trade (i.e., after controlling for the income and TFP differences across countries) and it is always positive. ${ }^{17}$ Aside from a rather obvious statement that a country gains from trade if its income (and TFP) ends up being higher than the world average, Proposition 3 cannot offer much insight on the overall welfare effects of trade in the absence of an explicit solution for eq.(30).

As $J \rightarrow \infty$, the task of evaluating the overall welfare effect becomes greatly simplified. By setting $x^{*}=j / J$ and $x=k / J$ in eq. (33) and noting that $\omega_{j} / \omega_{k} \rightarrow \Phi^{\prime}\left(x^{*}\right) / \Phi^{\prime}(x)$ and $S_{k}-S_{k-1} \rightarrow \Phi^{\prime}(x) d x$ as $J \rightarrow \infty$, eq.(33) converges to:

$$
\log \left(\frac{U\left(x^{*}\right)}{U^{A}}\right)=\int_{0}^{1} \log \left(\frac{\Phi^{\prime}\left(x^{*}\right)}{\Phi^{\prime}(x)}\right) \Phi^{\prime}(x) d x+\theta \int_{0}^{1} \gamma(\Phi(x)) \log \left(\frac{\gamma(\Phi(x))}{\Gamma_{A}}\right) \Phi^{\prime}(x) d x .
$$

Since $\log \left(\Phi^{\prime}(x)\right)-\theta \gamma(\Phi(x))=c_{0}$, this can be rewritten as:

$$
\begin{gathered}
\frac{1}{\theta} \log \left(\frac{U\left(x^{*}\right)}{U^{A}}\right)=\int_{0}^{1}\left(\gamma\left(\Phi\left(x^{*}\right)\right)-\gamma(\Phi(x))\right) \Phi^{\prime}(x) d x+\int_{0}^{1} \gamma(\Phi(x)) \log \left(\frac{\gamma(\Phi(x))}{\Gamma^{A}}\right) \Phi^{\prime}(x) d x \\
=\int_{0}^{1}\left(\gamma\left(s^{*}\right)-\gamma(s)\right) d s+\int_{0}^{1} \gamma(s) \log \left(\frac{\gamma(s)}{\Gamma^{A}}\right) d s=\gamma\left(s^{*}\right)-\Gamma^{A}+\int_{0}^{1} \gamma(s) \log \left(\frac{\gamma(s)}{\Gamma^{A}}\right) d s
\end{gathered}
$$

To summarize:

Proposition 4 (Limit case; $\boldsymbol{J} \rightarrow \infty$ ): The country that ends up being at $100 x^{*}$ percentile under trade gains from trade if and only if:

\footnotetext{
${ }^{17}$ To prove it, consider the convex maximization problem: $\underset{\left\{c_{k}\right\}_{k=1}}{\operatorname{Max}} \sum_{k=1}^{J} \Gamma_{k} \log \left(c_{k}\right)\left(S_{k}-S_{k-1}\right)$ s.t. $\sum_{k=1}^{J} c_{k}\left(S_{k}-S_{k-1}\right) \leq 1$. Although $c_{k}=1$ satisfies the constraint, its optimum is reached at $c_{k}=\Gamma_{k} / \Gamma^{A}$, so that $\sum_{k=1}^{J} \Gamma_{k} \log \left(\Gamma_{k} / \Gamma^{A}\right)\left(S_{k}-S_{k-1}\right)$ $>\sum_{k=1}^{J} \Gamma_{k} \log (1)\left(S_{k}-S_{k-1}\right)=0$.
} 


$$
\log \left(\frac{U\left(x^{*}\right)}{U^{A}}\right)=\theta\left[\gamma\left(s^{*}\right)-\Gamma^{A}+\int_{0}^{1} \gamma(s) \log \left(\frac{\gamma(s)}{\Gamma^{A}}\right) d s\right]>0,
$$

where $s^{*}=\Phi\left(x^{*}\right)$ or $x^{*}=\Phi^{-1}\left(s^{*}\right)$.

As in Proposition 3, Proposition 4 offers a decomposition of the welfare effects of trade. The first term,

$$
\gamma\left(s^{*}\right)-\Gamma^{A}=\gamma\left(\Phi\left(x^{*}\right)\right)-\Gamma^{A},
$$

represents the size of local service sector, which affects TFP of the economy, relative to the world average and relative to the autarky. This term is increasing in $s^{*}=\Phi\left(x^{*}\right)$, negative at $x^{*}$ $=0$ and positive at $x^{*}=1$. The second term,

$$
\int_{0}^{1} \gamma(s) \log \left(\frac{\gamma(s)}{\Gamma^{A}}\right) d s>0
$$

represents the usual gains from trade (i.e., controlling for the productivity differences across countries) and it is always positive. ${ }^{18}$ This implies that $\gamma\left(s^{*}\right)=\gamma\left(\Phi\left(x^{*}\right)\right) \geq \Gamma^{A}$ is a sufficient condition that a country gains from trade. In fact, Proposition 4 allows us to say a lot more about the overall welfare effects of trade, which are given in the following two Corollaries.

Corollary 1: All countries gain from trade if and only if

$$
\frac{\gamma(0)}{\Gamma^{A}} \geq 1-\int_{0}^{1}\left(\frac{\gamma(s)}{\Gamma^{A}}\right) \log \left(\frac{\gamma(s)}{\Gamma^{A}}\right) d s .
$$

The following example shows that Corollary 1 is not vacuous.

Example 4: $\gamma(s)=s^{\eta}, \eta>0$. Since $\gamma(0)=0,(35)$ can be rewritten as

$$
\int_{0}^{1}\left(\gamma(s) / \Gamma^{A}\right) \log \left(\gamma(s) / \Gamma^{A}\right) d s=\log (1+\eta)-\eta /(1+\eta)>1, \text { which holds for a sufficiently large } \eta .
$$

Quite remarkably, the sufficient and necessary condition under which all countries gain from trade, (35), depends solely on $\gamma(\bullet)$. In particular, it is independent of $\theta$, which only plays a role of magnifying the gains and losses from trade.

\footnotetext{
${ }^{18}$ To prove it, consider the convex maximization problem; $\underset{c(s) ; s \in[0,1]}{\operatorname{Max}} \int_{0}^{1} \gamma(s) \log (c(s)) d s$ subject to $\int_{0}^{1} c(s) d s \leq 1$. Although $c(s)=1$ satisfies the constraint, its optimum is reached at $c(s)=\gamma(s) / \Gamma^{A}$, hence $\int_{0}^{1} \gamma(s) \log \left(\gamma(s) / \Gamma^{A}\right) d s>$ $\int_{0}^{1} \gamma(s) \log (1) d s=0$.
} 
Corollary 2: Suppose that (35) fails. Then, there exists $s_{c}>0$, defined by

$$
\gamma\left(s_{c}\right) \equiv \Gamma^{A}\left[1-\int_{0}^{1}\left(\frac{\gamma(s)}{\Gamma^{A}}\right) \log \left(\frac{\gamma(s)}{\Gamma^{A}}\right) d s\right],
$$

such that

a): All countries producing and exporting goods $s \in\left[0, s_{c}\right)$ lose from trade, while all countries producing and exporting goods $s \in\left(s_{c}, 1\right]$ gain from trade.

b): The fraction of the countries that lose from trade, $x_{c}$, is given by $s_{c}=\Phi\left(x_{c} ; \theta\right)$, or equivalently, $x_{c}=H\left(s_{c} ; \theta\right)>s_{c}>0$. This is increasing in $\theta$ and $\lim _{\theta \rightarrow 0} x_{c}=\lim _{\theta \rightarrow 0} H\left(s_{c} ; \theta\right)=s_{c}$; $\lim _{\theta \rightarrow \infty} x_{c}=\lim _{\theta \rightarrow \infty} H\left(s_{c} ; \theta\right)=1$.

Note that $s_{c}$ depends solely on $\gamma(\bullet)$ and is independent of $\theta$. However, $x_{c}$ is increasing in $\theta$. Corollary $2 \mathrm{~b}$ states that, as $\theta$ increases from 0 to $\infty$ (i.e., as $\sigma$ declines from $\infty$ to 1 ), it increases from $s_{c}$ to 1 . In other words, with a $\gamma$ function that satisfies the condition under which some countries lose from trade, almost all countries can lose from trade as $\sigma \rightarrow 1$.

Example 5; Let $\gamma(s)=s$. Then, $\log \left(U\left(x^{*}\right) / U^{A}\right)=\theta\left(s^{*}-1 / 2+\int_{0}^{1} s \log (2 s) d s\right)$, from which

$$
s_{c} \equiv 3 / 4-(\log 2) / 2 \cong 40.3 \% ; \quad x_{c}=H\left(s_{c}\right)=\frac{1-e^{-\theta_{c}}}{1-e^{-\theta}},
$$

so that less than one half of the world gains from trade at $\theta=0.8$; less than one third at $\theta=2.3$; less than one fourth at $\theta=3.2$; less than one fifth at $\theta=3.8$, less than one tenth at $\theta=5.8$, and so on.

\section{Two Extensions}

The above model can be generalized in many directions. This section offers two extensions. The first allows a fraction of the consumption goods within each sector to be nontradeable. By reducing the fraction, this extension enables us to examine how inequality across countries is affected by globalization through trade in goods. The second allows variable supply in one of the components in the composite of primary factors, either through factor accumulation or factor mobility. By changing the share of the variable primary factor in the composite, this extension enables us to examine how inequality across countries is affected by 
technological change that increases importance of human capital or by globalization through trade in factors.

\subsection{Nontradeable Consumption Goods: Globalization through Trade in Goods}

In the above model, all consumption goods are assumed to be tradeable. Assume now that each sector-s produces many varieties, a fraction $\tau$ of which is tradeable and a fraction $1-\tau$ is nontradeable, and that they are aggregated by Cobb-Douglas preferences. ${ }^{19}$ The expenditure function is now obtained by replacing $\log (P(s))$ with $\tau \log \left(P_{T}(s)\right)+(1-\tau) \log \left(P_{N}(s)\right)$ for each $s$ $\in[0,1]$, where $\left.P_{T}(s)=\operatorname{Min}\left\{C_{j}(s)\right)\right\}$ is the price of each tradeable good in sector-s, common across all countries, $P_{N}(s)=C_{j}(s)$ is the price of each nontradeable good in sector-s, which is equal to the unit of cost of production in each country.

Instead of going through the entire derivation of the equilibrium, only the key steps will be highlighted below. Again, let $\left\{n_{j}\right\}_{j=1}^{J}$ be a monotone increasing sequence. As before, the patterns of trade and the free entry condition lead to

$$
\begin{array}{ll}
\frac{\omega_{j+1}}{\omega_{j}}=\left(\frac{n_{j+1}}{n_{j}}\right)^{\theta \gamma\left(S_{j}\right)}>1 . & (j=1,2, \ldots, J-1) \\
Y_{j}=\omega_{j} V=\left(S_{j}-S_{j-1}\right) Y^{W} . & (j=1,2, \ldots, J)
\end{array}
$$

However, the equilibrium variety of the local service sector is now given by, instead of (28):

$$
n_{j}=\left(\tau \Gamma_{j}+(1-\tau) \Gamma^{A}\right)\left(\frac{v}{(1+v)}\right)\left(\frac{V}{f}\right) .
$$

Combining these equations yields

Proposition 5 (J-country case): Let $\Phi^{J}:[0,1] \rightarrow[0,1]$ denote the Lorenz curve in GDP and TFP, the piece-wise linear function satisfying $\Phi^{J}(j / J)=S_{j}$. Then, $\left\{S_{j}\right\}_{j=0}^{J}$ solves the following

\footnotetext{
${ }^{19}$ This specification assumes that the share of local differentiated producer services in sector-s is $\gamma(s)$ for both nontradeables and tradeables. This assumption is made because, when examining the effect of globalization by changing $\tau$, we do not want the distribution of $\gamma$ across all tradeable consumption goods to change. However, for some other purposes, it would be useful to consider the case where the distribution of $\gamma$ among nontradeable consumption goods differ systematically from those among tradeable consumption goods. For example, Matsuyama (1996) allows for such possibility to generate a positive correlation between income and the nontradeable consumption goods prices across countries, similar to Balassa and Samuelson.
} 
nonlinear $2^{\text {nd }}$-order difference equation with the two terminal conditions:

$$
\frac{S_{j+1}-S_{j}}{S_{j}-S_{j-1}}=\left(\frac{\tau \Gamma\left(S_{j}, S_{j+1}\right)+(1-\tau) \Gamma^{A}}{\tau \Gamma\left(S_{j-1}, S_{j}\right)+(1-\tau) \Gamma^{A}}\right)^{\theta \gamma\left(S_{j}\right)}>1 \text { with } S_{0}=0 \& S_{J}=1,
$$

where $\Gamma\left(S_{j-1}, S_{j}\right) \equiv \frac{1}{S_{j}-S_{j-1}} \int_{S_{j-1}}^{S_{j}} \gamma(s) d s$

This equilibrium converges to a collection of $J$ identical single-country (autarky) equilibria as $\tau$

$\rightarrow 0$ and to the $J$-country trade equilibrium shown in Proposition 1, as $\tau \rightarrow 1$.

By following the same steps shown in section 2.5, one could obtain

\section{Proposition 6 (Limit Case; $J \rightarrow \infty$ ): The limit equilibrium Lorenz curve in GDP and TFP,} $\lim _{J \rightarrow \infty} \Phi^{J}=\Phi$, is characterized by the following nonlinear $2^{\text {nd }}$-order differential equation with the two terminal conditions:

$$
\frac{\Phi^{\prime \prime}(x)}{\Phi^{\prime}(x)}=\frac{\theta \gamma^{\prime}(\Phi(x)) \Phi^{\prime}(x)}{1+\Gamma^{A} / g \gamma(\Phi(x))} \text { with } \Phi(0)=0 \text { \& } \Phi(1)=1
$$

whose unique solution is:

$$
x=H(\Phi(x) ; g) \equiv \int_{0}^{\Phi(x)} h(s ; g) d s, \text { where } h(s ; g) \equiv \frac{\left[\left(1+g \gamma(s) / \Gamma^{A}\right)^{\Gamma^{A} / g} e^{-\gamma(s)}\right]^{\theta}}{\int_{0}^{1}\left[\left(1+g \gamma(u) / \Gamma^{A}\right)^{\Gamma^{A} / g} e^{-\gamma(u)}\right]^{\theta} d u},
$$

where $g \equiv \tau /(1-\tau)>0$.

Again, Figure 4 illustrates the solution. For each $g \equiv \tau /(1-\tau)>0, h(s ; g)$ is positive, and decreasing in $s$, and it is normalized so that its integral from 0 to 1 is equal to 1 . Thus, $H(s ; g)$ is increasing and concave in $s$, with $H(0 ; g)=0$ and $H(1 ; g)=1$. Hence, $\Phi(x ; g)=H^{-1}(x ; g)$ is increasing and convex in $x$, with $\Phi(0 ; g)=0$ and $\Phi(1 ; g)=1$. It is also easy to check

$$
\lim _{\tau \rightarrow 0} h(s ; g)=\lim _{g \rightarrow 0} h(s ; g)=1 .
$$

Thus, as $\tau \rightarrow 0$, each country converges to the same single-country (autarky) equilibrium and hence the Lorenz curve converges to the diagonal line, and inequality disappears. Likewise,

$$
\lim _{\tau \rightarrow 1} h(s ; g)=\lim _{g \rightarrow \infty} h(s ; g)=h(s) \equiv \frac{e^{-\theta \gamma(s)}}{\int_{0}^{1} e^{-\theta \gamma(u)} d u} .
$$

Thus, as $\tau \rightarrow 1$, the Lorenz curve converges to the one shown in Proposition 2. 
Indeed, a higher $\tau$, as well as a higher $\theta$, causes a Lorenz-dominant shift, as illustrated by the arrows in Figure 4. To see this, one just need to check that the numerator of $h(s ; g)$, $\hat{h}(s ; g) \equiv\left[\left(1+g \gamma(s) / \Gamma^{A}\right)^{\Gamma^{A} / g} e^{-\gamma(s)}\right]^{\theta}$, is log-submodular in $g$ and $s$ (and in $\theta$ and $s$ ). This means that both a higher $\tau$ (and a higher $\theta$ ) makes the graph of $h(s ; g)$ rotate "clockwise," as shown in the left panel, which in turn implies that the Lorenz curve becomes more "curved" and moves away from the diagonal line, as shown in the right panel. This result thus suggests that globalization through trade in goods leads to greater inequality across countries.

\subsection{Variable Factor Supply: Effects of Factor Mobility and/or Factor Accumulation}

Returning to the case where $\tau=1$, this subsection instead allows the available amount of the composite primary factors, $V$, to vary across countries by endogenizing the supply of one of the component factors, $K$, as follows:

$$
V_{j}=F\left(K_{j}, L\right) \quad \text { with } \quad \omega_{j} F_{K}\left(K_{j}, L\right)=\rho .
$$

where $F_{K}\left(K_{j}, L\right)$ is the first derivative of $F$ with respect to $K$, satisfying $F_{K K}$. In words, the supply of $K$ in the $j$-th country responds to its TFP, $\omega_{j}$, such that its factor price is equalized across countries at a common value, $\rho$. This can be justified in two different ways.

A. Factor Mobility: Imagine that $L$ represents (a composite of) factors that are immobile across borders and $K$ represents (a composite of) factors that are freely mobile across borders, which seek higher return until its return is equalized in equilibrium. ${ }^{20}$ According to this interpretation, $\rho$ is an equilibrium rate of return determined endogenously, although it is not necessary to solve for it when deriving the Lorenz curve. ${ }^{21}$

B. Factor Accumulation: Reinterpret the structure of the economy as follows. Time is continuous. All the tradeable goods, $s \in[0,1]$, are intermediate inputs that goes into the

\footnotetext{
${ }^{20}$ Which factors should be considered as mobile or immobile depends on the context. If "countries" are interpreted as "metropolitan areas," $K$ may include not only capital but also labor, with $L$ representing the immobile "land." Although labor is commonly included as immobile factors in the trade literature, we will later consider the possibility of trade in factors, in which case certain types of labor should be included among mobile factors. ${ }^{21}$ Also, $Y_{j}=V_{j}=\omega_{j} F\left(K_{j}, L\right)$ should be now interpreted as GDP of the economy, not GNP, and $K_{j}$ is the amount of $K$ used in the $j$-th country, not the amount of $K$ owned by the representative agent in the $j$-th country. This also means that the LHS of the budget constraint in the $j$-th country should be its GNP, not its GDP $\left(Y_{j}\right)$. However, calculating the distributions of GDP $\left(Y_{j}\right)$, TFP $\left(\omega_{j}\right)$, and $K_{j} / L$ does not require to use the budget constraint for each country, given that all consumption goods are tradeable $(\tau=1)$. The analysis would be more involved if $\tau<1$.
} 
production of a single final good, $Y_{\mathrm{t}}$, with the Cobb-Douglas function, $Y_{t}=\exp \left[\int_{0}^{1} \log \left(X_{t}(s)\right) d s\right]$ so that its unit cost is $\exp \left[\int_{0}^{1} \log \left(P_{t}(s)\right) d s\right]$. The representative agent in each country consumes and invests the final good to accumulate $K_{t}$, so as to maximize $\int_{0}^{\infty} u\left(C_{t}\right) e^{-\rho t} d t$ s.t. $Y_{t}=C_{t}+\dot{K}_{t}$, where $\rho$ is the subjective discount rate common across countries. Then, the steady state rate of return on $K$ is equalized at $\rho .{ }^{22}$ According to this interpretation, $K$ may include not only physical capital but also human capital, and the Lorenz curve derived below represents steady state inequality across countries.

Again, only the key steps will be shown. Let $\left\{n_{j}\right\}_{j=1}^{J}$ be monotone increasing. As before, $\left\{\omega_{j}\right\}_{j=1}^{J}$ adjust to ensure that there exists a monotone increasing sequence, $\left\{S_{j}\right\}_{j=1}^{J}$, defined by $S_{0}=$ $0, S_{J}=1$, and

$$
\frac{C_{j}\left(S_{j}\right)}{C_{j+1}\left(S_{j}\right)}=\left(\frac{n_{j}}{n_{j+1}}\right)^{-\theta \gamma\left(S_{j}\right)}\left(\frac{\omega_{j}}{\omega_{j+1}}\right)=1,
$$

such that the $j$-th country exports $s \in\left(S_{j}, S_{j+1}\right)$. This implies that, from (24) and (37),

$$
\frac{F_{K}\left(K_{j}, L\right)}{F_{K}\left(K_{j+1}, L\right)}=\frac{\omega_{j+1}}{\omega_{j}}=\left(\frac{n_{j+1}}{n_{j}}\right)^{\theta \gamma\left(S_{j}\right)}<1
$$

which implies that $\left\{\omega_{j}\right\}_{j=1}^{J},\left\{K_{j}\right\}_{j=1}^{J}$, and $\left\{V_{j}\right\}_{j=1}^{J}$ are all monotone increasing in $j$.

For the $j$-th country which produces $s \in\left(S_{j-1}, S_{j}\right)$, the factor market conditions can be combined to derive:

$$
\frac{\left(S_{j}-S_{j-1}\right) Y^{W}}{\omega_{j}}=\left(\frac{1+1 / v}{1+1 / v-\Gamma_{j}}\right)\left(V_{j}-n_{j} f\right) ; \quad v m q_{j}=\left(\frac{\Gamma_{j}}{1+1 / v-\Gamma_{j}}\right)\left(\frac{V_{j}}{n_{j}}-f\right)
$$

Hence, the free entry condition implies

$$
\begin{aligned}
& n_{j}=\Gamma_{j}\left(\frac{v V_{j}}{(1+v) f}\right)=\Gamma_{j}\left(\frac{v F\left(K_{j}, L\right)}{(1+v) f}\right) \\
& Y_{j}=\omega_{j} V_{j}=\omega_{j} F\left(K_{j}, L\right)=\left(S_{j}-S_{j-1}\right) Y^{W},
\end{aligned}
$$

\footnotetext{
${ }^{22}$ The intertemporal resource constraint assumes that $K$ is not mobile but also international lending and borrowing is not possible. Of course, these restrictions are not binding in steady state, because the rate of return is equalized at $\rho$
} 
so that the above equations can be summarized as:

$$
\left(\frac{S_{j+1}-S_{j}}{S_{j}-S_{j-1}}\right)\left(\frac{F\left(K_{j}, L\right)}{F\left(K_{j+1}, L\right)}\right)=\frac{F_{K}\left(K_{j}, L\right)}{F_{K}\left(K_{j+1}, L\right)}=\frac{\omega_{j+1}}{\omega_{j}}=\left(\frac{\Gamma_{j+1}}{\Gamma_{j}} \frac{F\left(K_{j+1}, L\right)}{F\left(K_{j}, L\right)}\right)^{\theta \gamma\left(S_{j}\right)}>1 .
$$

To see what is involved, suppose $V=F(K, L)=A K^{\alpha} L^{1-\alpha}$, with $0<\alpha<1-1 / \sigma=1 /(1+\theta)$. Then,

$$
\frac{Y_{j+1}}{Y_{j}}=\frac{\omega_{j+1} V_{j+1}}{\omega_{j} V_{j}}=\frac{K_{j+1}}{K_{j}}=\left(\frac{\omega_{j+1}}{\omega_{j}}\right)^{\frac{1}{1-\alpha}}=\left(\frac{V_{j+1}}{V_{j}}\right)^{\frac{1}{\alpha}}=\frac{S_{j+1}-S_{j}}{S_{j}-S_{j-1}}=\left(\frac{\Gamma_{j+1}}{\Gamma_{j}}\right)^{\frac{\theta \gamma\left(S_{j}\right)}{1-\alpha-\alpha \theta \gamma\left(S_{j}\right)}}>1
$$

from which

Proposition 7 (J-country case): Let $\Phi^{J}:[0,1] \rightarrow[0,1]$ denote the Lorenz curve in $Y$ and in $K / L$, the piece-wise linear function satisfying $\Phi^{J}(j / J)=S_{j}$. Then, $\left\{S_{j}\right\}_{j=0}^{J}$ solves the following nonlinear $2^{\text {nd }}$-order difference equation with the two terminal conditions:

$$
\frac{S_{j+1}-S_{j}}{S_{j}-S_{j-1}}=\left(\frac{\Gamma\left(S_{j}, S_{j+1}\right)}{\Gamma\left(S_{j-1}, S_{j}\right)}\right)^{\frac{\theta \gamma\left(S_{j}\right)}{1-\alpha-\alpha \theta \gamma\left(S_{j}\right)}}>1 \text { with } S_{0}=0 \& S_{J}=1
$$

where $\Gamma\left(S_{j-1}, S_{j}\right) \equiv \frac{1}{S_{j}-S_{j-1}} \int_{S_{j-1}}^{S_{j}} \gamma(s) d s$

It should be emphasized that $\Phi^{J}:[0,1] \rightarrow[0,1]$ represents the Lorenz curve in $Y$ and in $K / L$, not in TFP. However, the distribution of TFP can be obtained from the distribution of $Y$ (or $K / L$ ), using a monotone transformation, $\omega_{j+1} / \omega_{j}=\left(Y_{j+1} / Y_{j}\right)^{1-\alpha}$.

Following the same steps shown in section 2.5,

Proposition 8 (Limit Case; $\boldsymbol{J} \rightarrow \infty$ ): The limit equilibrium Lorenz curve, $\lim _{J \rightarrow \infty} \Phi^{J}=\Phi$, in $Y$ and in $K / L$, is characterized by the following nonlinear $2^{\text {nd }}$-order differential equation with the two terminal conditions:

$$
\frac{\Phi^{\prime \prime}(x)}{\Phi^{\prime}(x)}=\frac{\theta \gamma^{\prime}(\Phi(x)) \Phi^{\prime}(x)}{1-\alpha-\alpha \theta \gamma(\Phi(x))} \text { with } \Phi(0)=0 \& \Phi(1)=1
$$

whose unique solution is given by: 


$$
x=H(\Phi(x) ; \alpha) \equiv \int_{0}^{\Phi(x)} h(s ; \alpha) d s, \text { where } h(s ; \alpha) \equiv \frac{\left(1-\frac{\alpha \theta}{1-\alpha} \gamma(s)\right)^{1 / \alpha}}{\int_{0}^{1}\left(1-\frac{\alpha \theta}{1-\alpha} \gamma(u)\right)^{1 / \alpha} d u} .
$$

Again, Figure 4 illustrates the unique solution. For each $\alpha<1-1 / \sigma=1 /(1+\theta), h(s ; \alpha)$ is positive, and decreasing in $s$, and it is normalized so that its integral from 0 to 1 is equal to 1 . Thus, $H(s ; \alpha)$ is increasing and concave in $s$, with $H(0 ; \alpha)=0$ and $H(1 ; \alpha)=1$. Hence, $\Phi(x ; \alpha)=H^{-1}(x ; \alpha)$ is increasing and convex in $x$, with $\Phi(0 ; \alpha)=0$ and $\Phi(1 ; \alpha)=1$. It is also easy to check

$$
\lim _{\alpha \rightarrow 0} h(s ; \alpha) \equiv \frac{e^{-\theta \gamma(s)}}{\int_{0}^{1} e^{-\theta \gamma(u)} d u} .
$$

Thus, as $\alpha \rightarrow 0$, the solution converges to the Lorenz curve shown in Proposition 2.

Indeed, a higher $\alpha$, as well as a higher $\theta$, causes a Lorenz-dominant shift, as illustrated by the arrows in Figure 4. The reasoning should be familiar by now. The numerator of $h(s ; \alpha)$,

$$
\hat{h}(s ; \alpha) \equiv\left(1-\frac{\alpha \theta}{1-\alpha} \gamma(s)\right)^{1 / \alpha},
$$

is $\log$-submodular in $\alpha$ and $s$ (and in $\theta$ and $s$ ). Thus, a higher $\alpha$ (and a higher $\theta$ ) makes the graph of $h(s ; \alpha)$ rotate "clockwise," as shown in the left panel, which in turn implies that the Lorenz curve becomes more "curved" and moves away from the diagonal line, as shown in the right panel. This result suggests that skill-biased technological change that increases the share of human capital and reduces the share of raw labor in production, or globalization through trade in some factors, both of which can be interpreted as an increase in $\alpha$, could lead to greater inequality across countries.

\section{Concluding Remarks}

In cross-section of countries, the rich tend to have higher TFPs and higher capital-labor ratios. Such empirical findings are typically interpreted as the causality from TFPs and/or capital-labor ratios to income under two maintained hypotheses; i) these countries offer independent observations and ii) any variations in endogenous variables across countries would disappear in the absence of any exogenous sources of variations across countries. The model 
presented above offers some cautions for such an interpretation of cross-country variations. Despite that countries are ex-ante identical, the model predicts that a strict ranking of countries in income, TFPs, and capital-labor ratios (and other endogenous variables) emerge endogenously, and these variables are all jointly determined, and (perfectly) correlated across countries. This occurs because the countries end up sorting themselves into specializing in different sets of countries. In other words, some countries become richer (poorer) than others partly because they trade with poorer (richer) countries, so these countries do not offer independent observations. Of course, there have been other studies that deliver a similar message. In contrast to such earlier studies, which all used a highly stylized framework, the model here has advantage that it allows for any finite number of countries and offers a full characterization of the equilibrium Lorenz curve across countries with quantitative implications in an analytically tractable manner. 
Figure 1: Comparative Advantage and Patterns of Trade in the Two-Country World

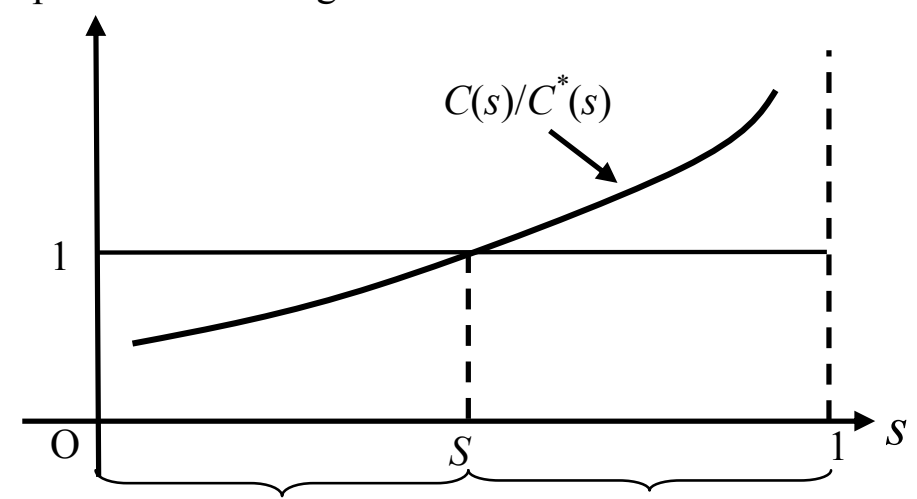

Home Exports Foreign Exports

Figure 2: Comparative Advantage and Patterns of Trade in the $J$-country World

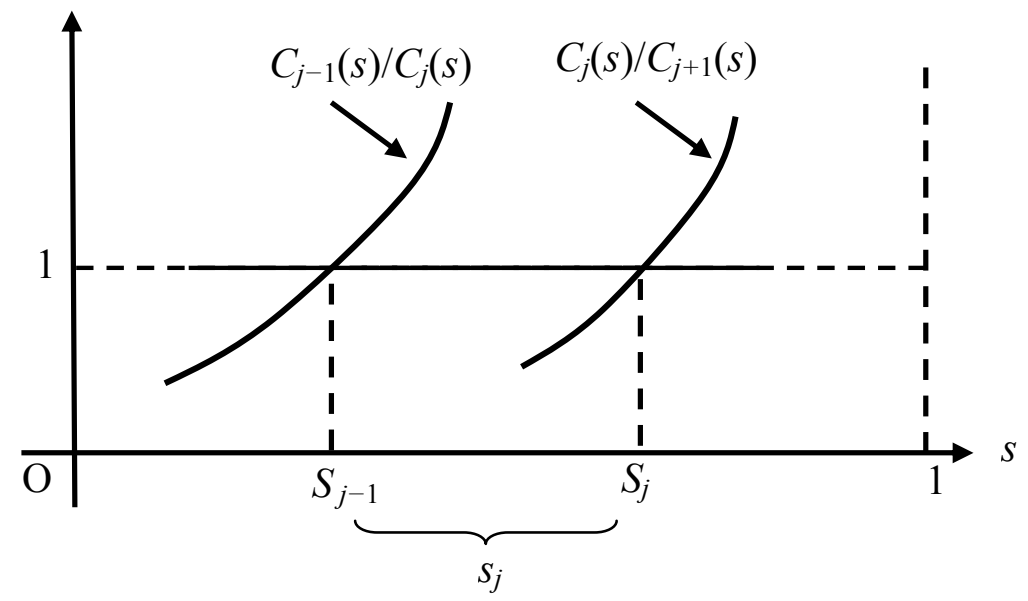


Figure 3: Equilibrium Lorenz curve, $\Phi^{J}$ : A Graphic Illustration for $J=4$

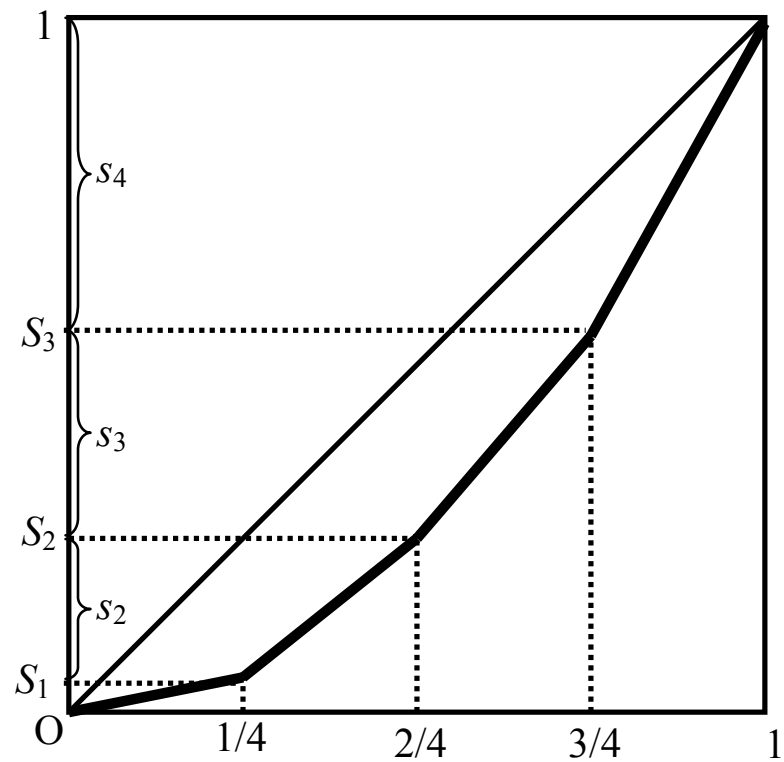

Figure 4: Limit Equilibrium Lorenz Curve, $\Phi(x)$, and its Lorenz-dominant Shift
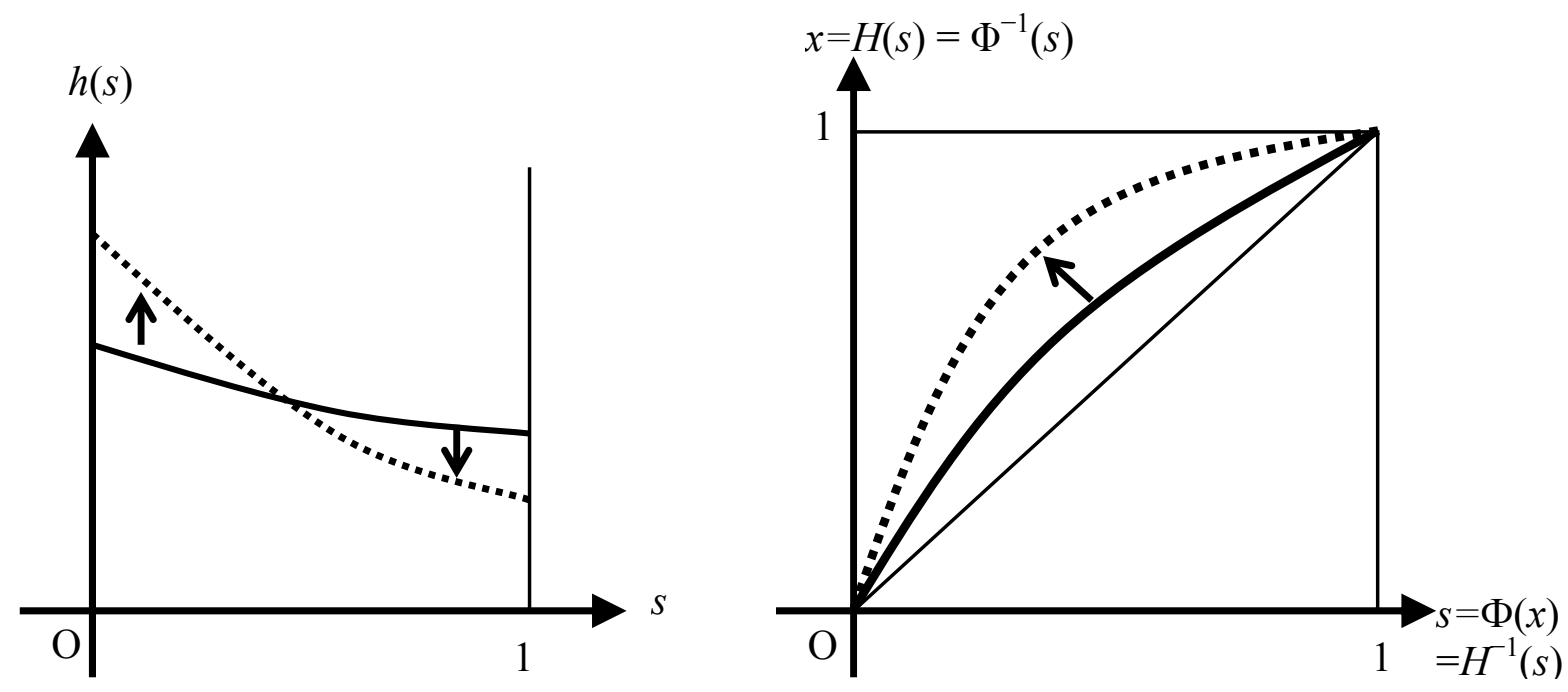


\section{References:}

Acemoglu, D., Introduction to Modern Economic Growth, Princeton University Press, 2008.

Acemoglu, D., and J. Ventura, “The World Income Distribution,” Quarterly Journal of Economics, 117 (2002), 659-694.

Combes, P.-P., T. Mayer and J. Thisse, Economic Geography, Princeton University Press, 2008.

Costinot, A., (2009), "An Elementary Theory of Comparative Advantage," Econometrica, 11651192.

Dixit, A. K., and J. E. Stiglitz, "Monopolistic Competition and Optimum Product Diversity," American Economic Review, 1977, 297-308.

Dornbusch, R., S. Fischer and P. A. Samuelson, "Comparative Advantage, Trade, and Payments in a Ricardian Model with a Continuum of Goods," American Economic Review, 67 (1977), 823-839.

Ethier, W., "National and International Returns to Scale in the Modern Theory of International Trade," American Economic Review, 72, 1982, 389-405.

Fujita, M., P., Krugman, P. and A. Venables, The Spatial Economy, MIT Press, 1999.

Ioannides, Y., "Emergence," in L. Blume and S. Durlauf, eds., New Palgrave Dictionary of Economics, $2^{\text {nd }}$ Edition, Palgrave Macmillan, 2008.

Jovanovic, B., "Vintage Capital and Inequality," Review of Economic Dynamics, (1998), 497530.

Jovanovic, B., "The Technology Cycle and Inequality," Review of Economic Studies, (2009) 707-729.

Krugman, P. and A. Venables, "Globalization and Inequality of Nations," Quarterly Journal of Economics, 110 (1995), 857-80.

Matsuyama, K., "Why Are There Rich and Poor Countries?: Symmetry-Breaking in the World Economy," Journal of the Japanese and International Economies, 10 (1996), 419-439.

Matsuyama, K., and T. Takahashi, "Self-Defeating Regional Concentration," Review of Economic Studies, 65 (April 1998): 211-234.

Matsuyama, K., "Symmetry-Breaking" in L. Blume and S. Durlauf, eds., New Palgrave Dictionary of Economics, $2^{\text {nd }}$ Edition, Palgrave Macmillan, 2008.

Romer, P., "Growth Based on Increasing Returns Due to Specialization," American Economic Review, 77 (1987), 56-62.

Topkis, D., Supermodularity and Complementarity, Princeton University Press, 1998. Ventura, J., "A Global View of Economic Growth," in P. Aghion and S. N. Durlauf, eds., Handbook of Economic Growth. Vol, IB, Amsterdam, Elsevier BV, 2005. 